\title{
PREDICTING COMPACTION GROUT QUANTITIES IN SINKHOLE REMEDIATION
}

\author{
Edward D. Zisman \\ Cardno ATC, 5602 Thompson Center Court, Suite 405, Tampa, Florida 34689
}

\begin{abstract}
Predicting the required quantity of grout needed to remediate a sinkhole-damaged home is a challenging task that involves significant amounts of uncertainty. The difficulty arises from the limited amount of subsurface information that is available to make subsurface predictions particularly in complex karst environments. In typical sinkhole investigations, our understanding of the subsurface is limited by the three to four data points (borings) that provide a small window into actual subsurface conditions. This information is normally obtained from borings and from information inferred by geophysical surveys. In many cases, the information is not sufficient to make accurate predictions of grout quantities. This paper will discuss the uncertainties in analyzing the many factors that influence grout prediction; it will provide a method of calculating grout quantities and discuss how one may moderate the difficulties in prediction of grout quantities. Examples of case studies are given showing pre-grout and postgrout information and the lessons learned from these comparisons.
\end{abstract}

\section{Introduction}

This paper is based on experiences with compaction grout in Florida and in particular in west-central Florida. A large percentage of the remediation investigations and grout monitoring projects have been performed for insurance companies who would like estimated and actual grout quantities to be reasonably close.

A factor in writing this paper was to elicit comments on the method presented here to ultimately provide the grouting community with a method that more accurately predicts grout quantities.

The prediction of grout quantities is an imprecise practice; it is imprecise because we are trying to measure conditions that are irregular in both vertical and horizontal directions. These conditions result from variable chemical and mechanical weathering patterns that serve to complicate subsurface conditions. Compounding the problems with interpreting complex subsurface conditions is that we have direct information about these conditions from only three or four borings. In the absence of more definitive information we are required to extrapolate over large distances to fill in the sizeable amounts of missing information. Furthermore, since the karst subsurface is not uniform, the complexity of the subsurface becomes a controlling factor in the accuracy of grout predictions.

In many cases the equations we use to calculate grout quantities provide weighted averages for assumed conditions located 20 feet (6.1 meters) or 50 feet (15.2 meters) apart.

Extrapolation between distant data points and variability in such factors as porosity, soil composition, induration etc. compromise the accuracy we obtain in our grout models. In this paper we will discuss the causes of subsurface variability and methods we can use to mitigate them.

\section{Cost of Compaction Grouting}

When damage in a building is caused by active sinkhole conditions, owners and insurance companies are anxious to determine the cost of repair. A major expense in remediation is the quantity of compaction grout needed for remediation. Typically, average grout quantities range from 200 cubic yards ( 152.9 cubic meters) to 500 cubic yards (382.3 cubic meters) at a cost of approximately 175 dollars per cubic yard; this can result in a cost for compaction grout alone of from $\$ 35,000$ to $\$ 87,500$. Adding to the grout cost is the cost for drilling grout holes, chemical grout and monitoring. These other costs can easily cause the total to reach $\$ 100,000$ or more.

\section{Subsurface Information}

As stated, most grout estimates are based on assumed subsurface conditions defined by essentially three or four borings and a geophysical survey. The completeness of this information is dependent on the complexity of the subsurface. To illustrate this, consider the idealized subsurface conditions shown in Figures 1 and 2. In Figure 1 where the subsurface is relatively uniform 


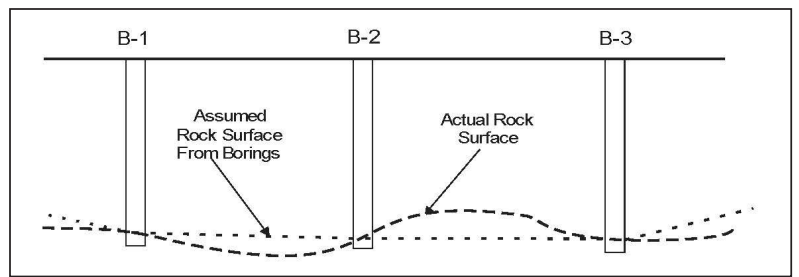

Figure 1. Relatively uniform rock surface.

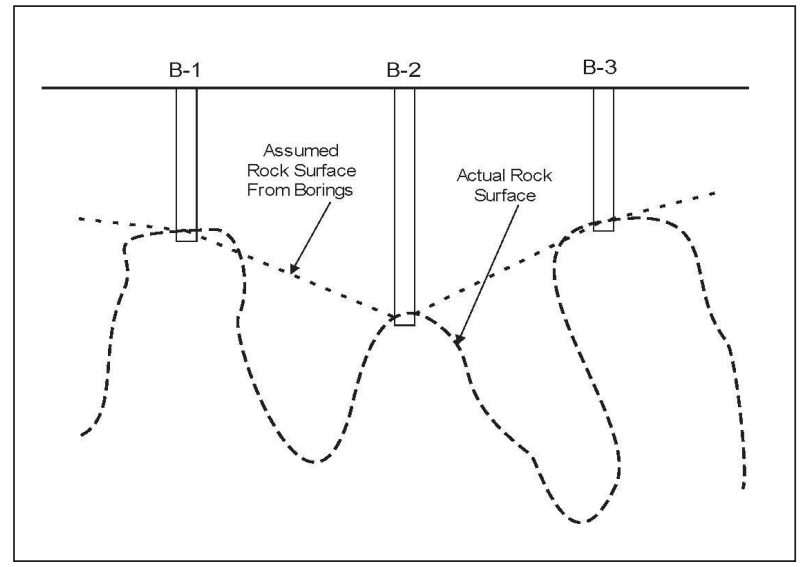

Figure 2. Very irregular rock surface.

grout estimates can be made with an accuracy of from approximately 10 to $20 \%$. However, in Figure 2, where the variation between the actual rock surface and the assumed rock surface is very large, the accuracy of grout predictions can easily exceed 50 to $100 \%$ of the estimate.

The reason for this diversity is karst processes are complex and we cannot accurately predict their occurrence with the limited subsurface information normally available. Furthermore, information obtained from geophysical surveys is limited by the sensitivity of the method to soil type, budget constraints, environmental conditions etc. In addition, the geophysical data must be verified by borings. In reality we only see less than $1 \%$ of the soil material under the footprint of the building (Zisman and Clarey, 2013).

\section{Calculation of Grout Quantities Unknowns}

Up to now it has been discussed that grout is expensive and difficult to predict where and in what quantity it will be needed. Unfortunately, it is not possible to write an equation to quantify what is not known. What can be done is we can minimize the unknowns by being alert to likely excursions in the soil profile. For example: are N-values uniform (is there continuity in lithology from one boring to another), is there a great difference between the depth to rock or depth to soft material from one boring to another, is there loss of circulation in all or some of the borings, is the rock surface highly weathered etc. These and other factors are signs of potential problems in predicting grout quantities.

\section{Method}

Equation 1 is the method used to calculate grout quantities. The equation is rather simple; it calculates the volume of grout cylinder injected into the ground considering the thickness of each sequence of unique soil found in the borings. Factors are added for the assumed porosity, void reduction, continuity and uncertainty of each material found in the borings. The problem with this calculation is that it is greatly dependent on the information obtained in the borings and in particular on the assumed extent and variation of the soil properties occurring between boring locations. The illustrations in Figures 1 and 2 provide examples of potential variations in the limestone surface (and potentially in variations in the soil conditions occurring above the limestone). In most cases, the greater the variation in the surface of the rock, the greater the likelihood for error in estimates of grout quantities.

In Figure 1 the rock conditions are relatively uniform and grout estimates are generally more accurate. In contrast, Figure 2 shows a relatively irregular rock surface where prediction of grout quantities is difficult because of the irregular rock surface and the greater error that occurs in interpreting between borings. In fact, depending where the boring samples the rock surface, one may be misled into assuming the conditions in Figure 2 are the same as in Figure 1.

Equation 1 (Hussin, 2012) is as follows:

$$
\mathrm{Gp}=\mathrm{T} \times \pi \times \mathrm{r}^{2} \times \mathrm{n} \times \operatorname{Vr} \times \mathrm{UF}
$$

Where:

$\mathrm{T}=$ Thickness of soil to be grouted

$\mathrm{r}=$ radius of effective treatment area (typically 0.9

meters, reductions can be made for larger clayey

components found in the soil section)

$\mathrm{n}=$ Porosity $(\mathrm{Vv} / \mathrm{Vt})$ of dominant soil types. Typically:

(SMloose $=0.45$, SMdense $=0.25$; CLsoft $=0.55$,

CLstiff $=0.37$ )

$\mathrm{Vr}=$ Void reduction factor is the amount you expect the porosity to be reduced. $30 \%$ reduction is typical.

$\mathrm{Gp}=$ Amount of grout estimated per gout point

$\mathrm{UF}=$ Uncertainty factor $(10-75 \%)$. Depends on

confidence in soil location and composition, see text.

Number of Points $=$ Typically 8 to 10 -foot $(2.4$ to 3.0 meters) spacing around the perimeter of the building. 
Examples of Grout Quantity Determinations

Two examples are given of compaction grout determinations. Example 1 is illustrated in Figures 3, 4, and 5, while Example 2 is illustrated in Figures 6, 7, and 8. In Example 1, grout quantity was estimated to

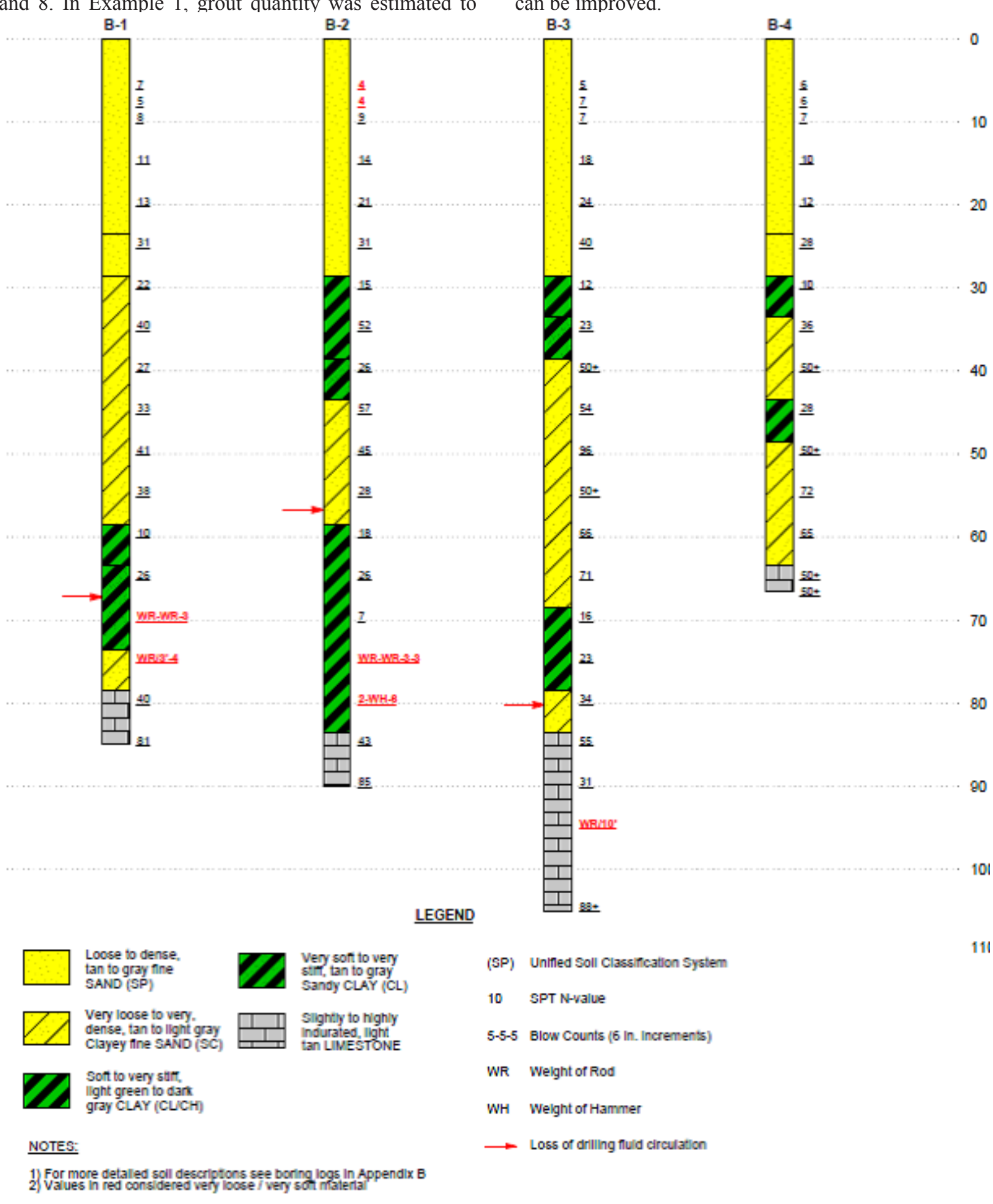

an accuracy of 92\%, while in Example 2 grout quantity was estimated to an accuracy of $69 \%$. In each of the examples, an explanation is given detailing the factors that help or hinder the determination and how accuracy can be improved.

50

80

101

Figure 3. Subsurface profile in Example 1. 


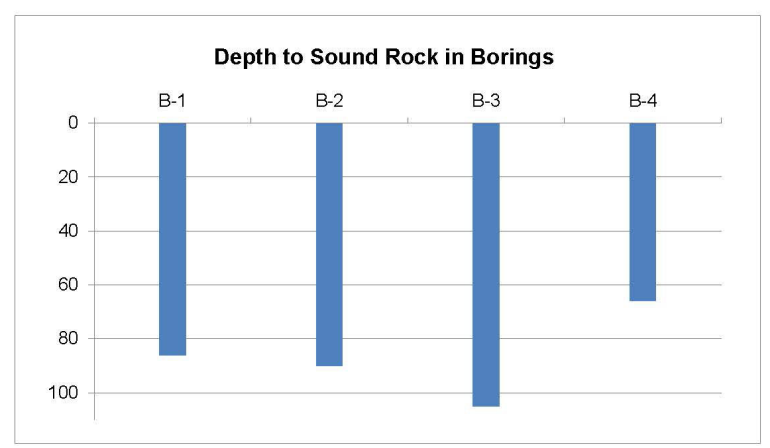

Figure 4. Depth to top of rock from borings in Example 1.
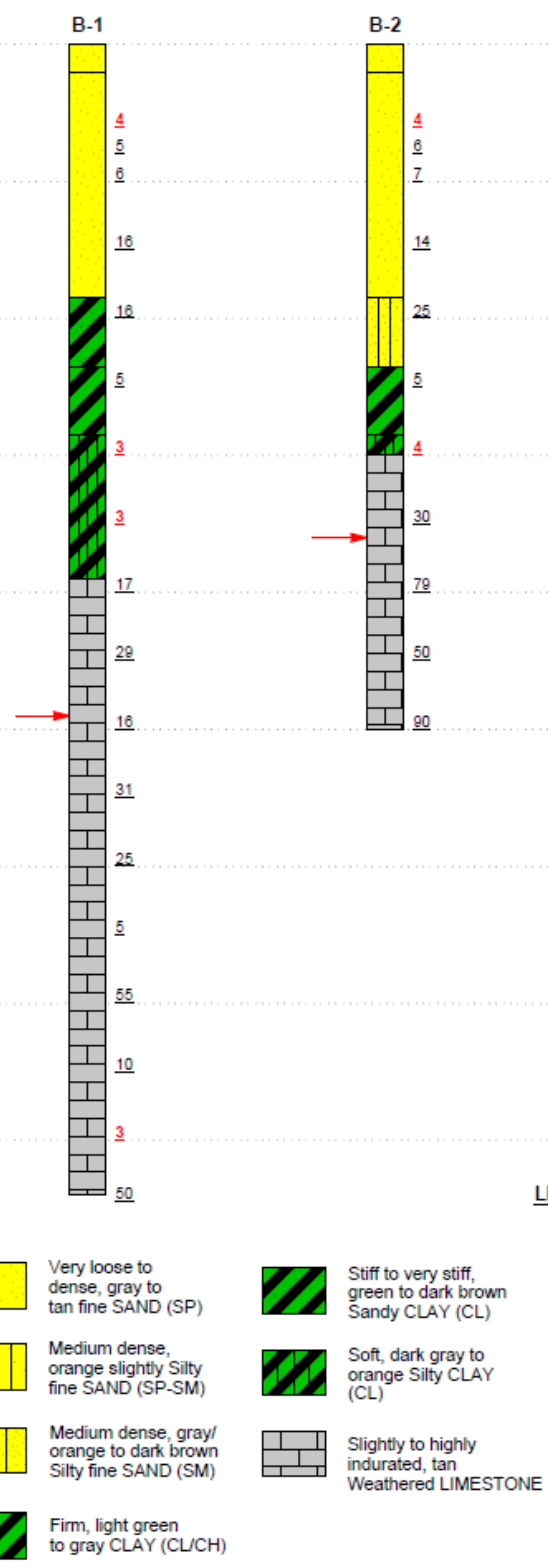

Figure 6. Subsurface profile in Example 2.

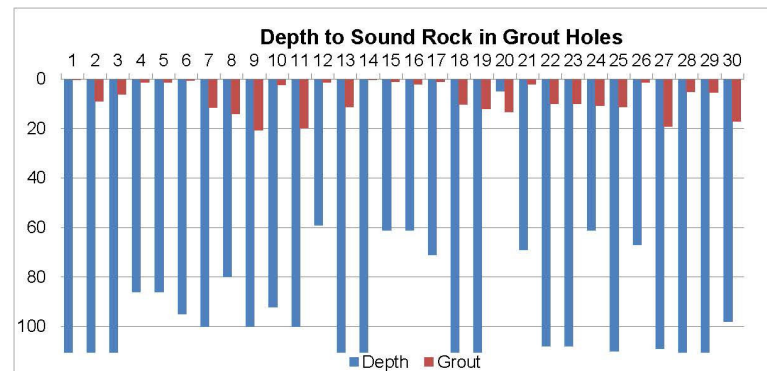

Figure 5. Depth to sound rock from grout holes in Example 1 along with relative amount of grout used.
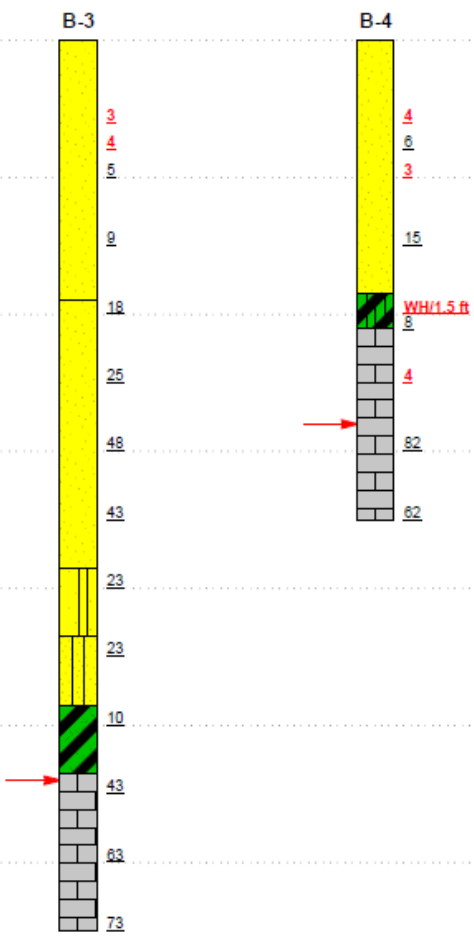

0

10

20

30

40

50

60

70

80

LEGEND

(SP) Unified Soil Classification System

90

10 SPT N-value

5-5-5 Blow Counts ( 6 in. increments)

WR Weight of Rod

WH Weight of Hammer

$\longrightarrow$ Loss of drilling fluid circulation

NOTES:

1) For more detailed soil descriptions see boring logs in Appendix B 


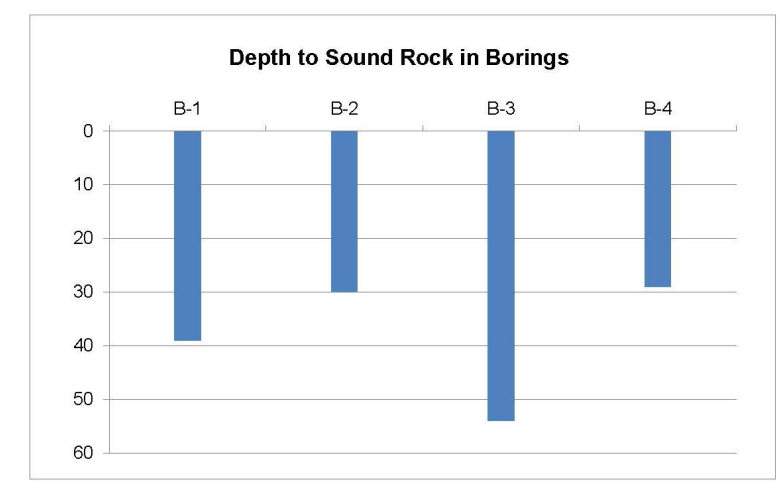

Figure 7. Depth to rock from borings in Example 2.

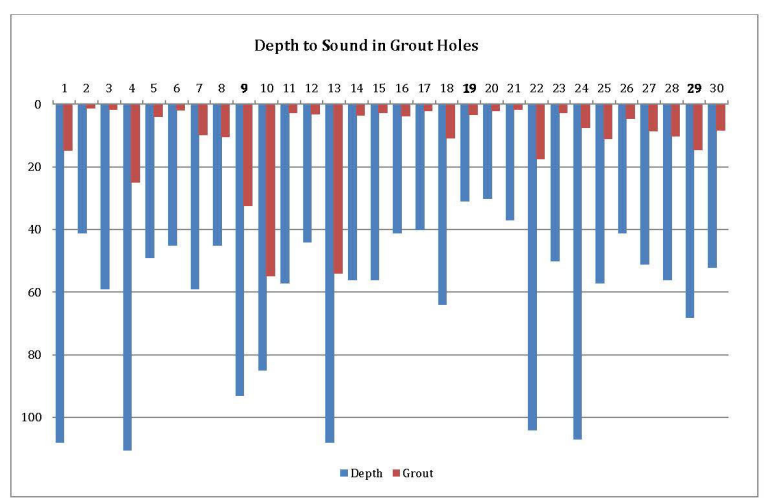

Figure 8. Depth to rock from grout holes in Example 2 along with relative amount of grout used.

The figures provided in each example show: 1) a profile of the conditions found in the borings, 2) a profile of the depth to rock found in the site borings and 3) a profile of the depth to rock found in the grout holes. On the grout hole depth to rock figure, the relative amount of grout pumped in each hole is shown. This was done to determine if there was a correlation between the depth of the drill hole and the amount of grout used.

\section{Example 1, Grout Prediction}

In Example 1, the overall soil profile generally consists of: dense to very dense soil from a depth of 10 feet ( 3.0 meters) to 65 feet (19.8 meters) below land surface (bls). This is followed by intervals of soft/ loose material at various depth intervals in three of the four borings. The soft/loose material found in this section (Figure 3) will account for the largest amount of grout, depending on the uniformity of the soft/loose zones. The dense soils, which make up the upper portion of the profile, will take substantially less grout. In some cases where relatively uniform $\mathrm{N}$-values are found, $\mathrm{CL}$ and SC material may be combined in calculation of grout quantities. This overall interpretation of the soil profile was used in the calculation shown in Table 1 and resulted in an overall accuracy of $92 \%$ in compaction grout prediction.

\section{Example 1 Discussion}

In Example 1, our estimate of grout volume provided a $92 \%$ prediction accuracy. The high accuracy in this example is the result of the relatively flat relief of the rock surface coupled with the limited extent of soft/loose soil conditions. These results are summarized in Table 3 where it is seen that a small difference was found in relief in the limestone surface determined from the borings compared to that determined from the grout holes. This small difference in relief ( 16 feet -4.9 meters) of the limestone rock surface measured from the results of four data points (borings) verses 35 data point (grout holes) further suggests the surface is relatively flat. In addition, the distribution of soil materials was more uniform and hence resulted in a more accurate estimation of soil variables used in grout prediction.

\section{Example 2, Grout Prediction}

Subsurface conditions in Example 2 are different than those in Example 1. First, the loose/soft material

Table 1. Calculation for Example 1.

\begin{tabular}{|c|c|c|c|c|c|c|c|c|c|c|c|c|c|}
\hline $\begin{array}{l}\text { Soil } \\
\text { No. }\end{array}$ & $\begin{array}{l}\text { Av. } \\
\text { NValue }\end{array}$ & $\begin{array}{l}\text { Soil } \\
\text { Type }\end{array}$ & $\begin{array}{l}\text { Dept } \\
\text { from }\end{array}$ & $\begin{array}{l}\text { (ft) } \\
\text { to }\end{array}$ & $\begin{array}{c}\mathrm{T} \\
\text { (ft) }\end{array}$ & $\begin{array}{l}r \\
\text { (ft) }\end{array}$ & n & VR & UF & 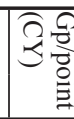 & 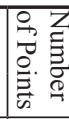 & 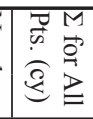 & 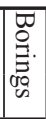 \\
\hline 1 & 18 & SM & 15 & 30 & 15 & 3 & 0.38 & 0.3 & 1.10 & 1.97 & 6 & 11.8 & $i_{1}^{\infty}$ \\
\hline 2 & 34 & $\mathrm{SC}$ & 30 & 60 & 30 & 3 & 0.30 & 0.2 & 1.20 & 2.26 & 6 & 13.6 & \\
\hline 3 & 18 & CL & 60 & 65 & 5 & 3 & 0.37 & 0.2 & 1.30 & 0.50 & 6 & 3.0 & \\
\hline 4 & 0 & SC-CL & 65 & 80 & 15 & 3 & 0.55 & 0.2 & 1.30 & 2.25 & 6 & 13.5 & \\
\hline \multicolumn{2}{|c|}{ Subtotal } & & & & & & & & & & & 41.9 & \\
\hline 1 & 22 & SN & 15 & 30 & 15 & 3 & 0.38 & 0.3 & 1.10 & 1.97 & 11 & 21.7 & 范 \\
\hline 2 & 31 & CL-SC & 30 & 60 & 30 & 3 & 0.40 & 0.3 & 1.30 & 4.90 & 11 & 53.9 & \\
\hline 3 & 16 & CL & 60 & 70 & 10 & 3 & 0.37 & 0.2 & 1.40 & 1.08 & 11 & 11.9 & \\
\hline 4 & 0 & $\mathrm{CI}$ & 70 & 85 & 15 & 3 & 55 & 0.2 & 1.40 & 2.42 & 11 & 26.6 & \\
\hline \multicolumn{2}{|c|}{ Subtotal } & & & & & & & & & & & 114.1 & \\
\hline 1 & 27 & SN & 15 & 30 & 15 & 3 & 0.3 & 0.3 & 1.10 & 1.55 & 10 & 15.5 & $\prod_{1}^{\infty}$ \\
\hline 2 & 17 & CL & 30 & 40 & 10 & 3 & 0.4 & 0.4 & 1.40 & 2.34 & 10 & 23.4 & \\
\hline 3 & $>50$ & $\mathrm{SC}$ & 40 & 70 & 30 & 3 & 0.3 & 0.3 & 1.20 & 3.39 & 10 & 33.9 & \\
\hline 4 & 19 & CL-SC & 70 & 80 & 10 & 3 & 0.4 & 0.4 & 1.30 & 2.18 & 10 & 21.8 & \\
\hline \multicolumn{2}{|c|}{ Subtotal } & & & & & & & & & & & 94.7 & \\
\hline 1 & 15 & SM-CL & 15 & 35 & 20 & 3 & 0.3 & 0.3 & $\mid 1.10$ & 2.07 & 8 & 16.6 & $\bar{\sigma}$ \\
\hline 2 & & SC-CL & 35 & 65 & 30 & 3 & 0.37 & 0.3 & 1.10 & 3.83 & 8 & 30.7 & \\
\hline \multicolumn{2}{|c|}{ Subtotal } & & & & & & & & & & & 47.3 & \\
\hline \multicolumn{2}{|c|}{ Grand Total } & & & & & & & & & & & 297.9 & \\
\hline
\end{tabular}


in Example 2 is in the upper part of the profile and its distribution appears to be more widespread. This suggests that a large part of the zone above the limestone may have to be grouted. Second, there is greater relief in the rock surface in Example 2. This greater variability in the rock surface translates into greater variability and complexity in the soil overlying the rock compounding errors in the nature and distribution of the soils.

A further indication that Example 2 will take more grout is the variability in thickness of the loose/soft zone and the more widespread distribution of this zone. An example of the grout calculation for Example 2 is shown in Table 2.

Table 2. Calculation for Example 2.

\begin{tabular}{|c|c|c|c|c|c|c|c|c|c|c|c|c|c|}
\hline $\begin{array}{l}\text { Soil } \\
\text { No. }\end{array}$ & $\begin{array}{l}\mathrm{N}- \\
\text { Value }\end{array}$ & $\begin{array}{l}\text { Soil } \\
\text { Type }\end{array}$ & from & to & (ft) & $\begin{array}{l}\mathrm{r} \\
\text { (ft) }\end{array}$ & $\mathrm{n}$ & $\mathrm{Vr}$ & UF & $\begin{array}{l}\frac{0}{2} \\
\frac{0}{0} \\
\vdots \\
0\end{array}$ & 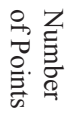 & 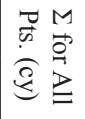 & 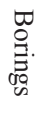 \\
\hline 1 & 10 & SP & 10 & 18 & 8 & 3 & 0.3 & 0.3 & 1.20 & 0.90 & 7 & 6.3 & $\underset{1}{\sigma}$ \\
\hline 2 & 3 & $\mathrm{CL}$ & 18 & 38 & 20 & 3 & 0.6 & 0.4 & 1.75 & 8.79 & 7 & 61.5 & \\
\hline 3 & 30 & LS & 38 & 70 & 32 & 3 & 0.4 & 0.3 & 1.20 & 4.82 & 7 & 33.8 & \\
\hline \multicolumn{12}{|c|}{ Subtotal } & 101.6 & \\
\hline 1 & 14 & SP & 10 & 25 & 15 & 3 & 0.3 & 0.3 & 1.20 & 1.70 & 7 & 11.9 & \multirow{4}{*}{$\underset{\sim}{\mathbb{N}}$} \\
\hline 2 & 4 & CL & 25 & 30 & 5 & 3 & 0.6 & 0.4 & 1.75 & 2.20 & 7 & 15.4 & \\
\hline 3 & 50 & LS & 30 & 40 & 10 & 3 & 0.4 & 0.3 & 1.20 & 1.51 & 7 & 10.6 & \\
\hline \multicolumn{12}{|c|}{ Subtotal } & 37.8 & \\
\hline 1 & 25 & SP & 10 & 45 & 35 & 3 & 0.3 & 0.3 & 1.20 & 3.96 & 5 & 19.8 & \multirow{4}{*}{$\underset{\dot{\omega}}{\varpi}$} \\
\hline 2 & 10 & CL & 45 & 55 & 10 & 3 & 0.4 & 0.3 & 1.75 & 2.20 & 5 & 11.0 & \\
\hline 3 & 50 & LS & 55 & 60 & 5 & 3 & 0.4 & 0.3 & 1.20 & 0.75 & 5 & 3.8 & \\
\hline \multicolumn{12}{|c|}{ Subtotal } & 34.5 & \\
\hline 1 & 5 & SP & 10 & 20 & 10 & 3 & 0.3 & 0.3 & 1.20 & 1.13 & 11 & 12.4 & \multirow{4}{*}{$\varpi$} \\
\hline 2 & 0 & $\mathrm{CL}$ & 20 & 25 & 5 & 3 & 0.6 & 0.4 & 1.75 & 2.20 & 11 & 24.2 & \\
\hline 3 & 50 & LS & 25 & 35 & 10 & 3 & 0.4 & 0.3 & 1.20 & 1.51 & 11 & 16.6 & \\
\hline \multicolumn{12}{|c|}{ Subtotal } & 53.2 & \\
\hline \multicolumn{12}{|c|}{ Grand Total } & 227.2 & \\
\hline
\end{tabular}

Table 3. Comparison of grout quantities.

\begin{tabular}{|c|c|c|c|c|c|c|c|}
\hline 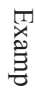 & $\begin{array}{l}\text { Limesto } \\
*(\text { feet } / \mathrm{m}\end{array}$ & $\begin{array}{l}\text { Relief } \\
\text { ers) }\end{array}$ & $\begin{array}{l}\underset{Ð}{Ð} \\
\stackrel{Ð}{\Xi}\end{array}$ & $\begin{array}{l}\text { Grout Qua } \\
(\mathrm{yd} 3 / \mathrm{m} 3)\end{array}$ & & & \\
\hline$z$ & Borings & $\begin{array}{l}\text { Grout } \\
\text { Holes }\end{array}$ & 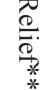 & Estimated & Actual & Acenracy & 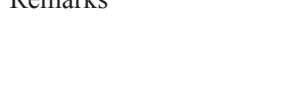 \\
\hline 1 & $21 / 6.4$ & $50 / 15.2$ & 29 & $285 / 218$ & $325 / 249$ & $88 \%$ & $\begin{array}{l}\text { Soft material occurs } \\
\text { below a depth of } 70 \text { feet } \\
\text { in the subsurface profile }\end{array}$ \\
\hline 2 & $25 / 7.6$ & $80 / 24.4$ & 55 & $227 / 174$ & $330 / 252$ & $69 \%$ & $\begin{array}{l}\text { Soft material occurs } \\
\text { above a depth of } 20 \text { feet } \\
\text { in the subsurface profile }\end{array}$ \\
\hline
\end{tabular}

*"Limestone Relief" is the difference in elevation between the highest and lowest expression of rock ** "Difference in Relief" is the difference between the limestone relief found in the grout holes minus the limestone relief found in the borings

\section{Example 2 Discussion}

Table 3 provides a comparison of the grout results in the two examples and helps to elucidate why more error occurred in the grout prediction of Example 2.

\section{Concluding Discussion}

The following is a summary of the conclusions reached in this paper:

1. We have small windows into the subsurface from the three or four borings drilled for the investigation. This limited amount of data may not give sufficient information into the composition of the subsurface. Figures 1 and 2 provide an illustration of this problem.

2. To compensate for the absence of detailed subsurface data, we must examine other cues that may be present in the subsurface. This information can be found in: historical air photos, grout information from neighboring homes, topographic relief of the regional ground surface, geologic history of the area etc.

3. Equation 1 can provide reasonably accurate $(+/-35 \%)$ predictions of grout quantities if we can rationally estimate the type and variability of the soil and rock conditions between boring locations. This requires use of incidental information from geology, aerial photography, topographic, neighboring homes etc.

4. The factors in Equation 1 should be applied judiciously. They should reflect the uncertainty in the subsurface.

5. We can expect higher grout quantities when the relief in the rock surface increases or if abrupt changes in lithology are found between the borings. Conversely, if the lithology is 
continuous from one boring to the next, we can make more accurate grout predictions.

6. An additional factor that can significantly impact the amount of grout placed for remediation is the manner in which the grout is placed. Figure 9 illustrates this problem. During grouting high pore pressures develop that can cause the soil to fail in an undrained state, remolding the soil into a liquefied mass. This causes an increase in the amount grout used and weakening of the subsurface. This condition can be mitigated by limiting the pressure and limiting the maximum amount of grout that can be placed in a 24-hour period in one grout point.

7. In the examples shown here, no strong correlation was found between grout hole depth and grout take. However, many factors were present that obscure this relationship, such as distance to boring, changing soil conditions, borehole conditions, etc.

8. It is hoped that this paper will encourage others to share their methods of predicting grout quantities and share their experience with using this or similar methods to predict grout quantities.

\section{References}

Hussin J. 2012. Compaction grouting. In: Kirsch, K and Bell, A (eds.), Ground Improvement, third edition, CRC Press.

Zisman ED, Clarey D. 2013. Problems associated with the use of compaction grout for sinkhole remediation in west-central Florida. In: Land L, Doctor DH, Stephenson JB, editors, Proceedings of the 13th Multidisciplinary Conference on Sinkholes and the Engineering and Environmental Impacts of Karst. Carlsbad, New Mexico, 5-10 May, p 23-26.
Grout Flow $<2-5 \mathrm{cf} / \mathrm{min}$

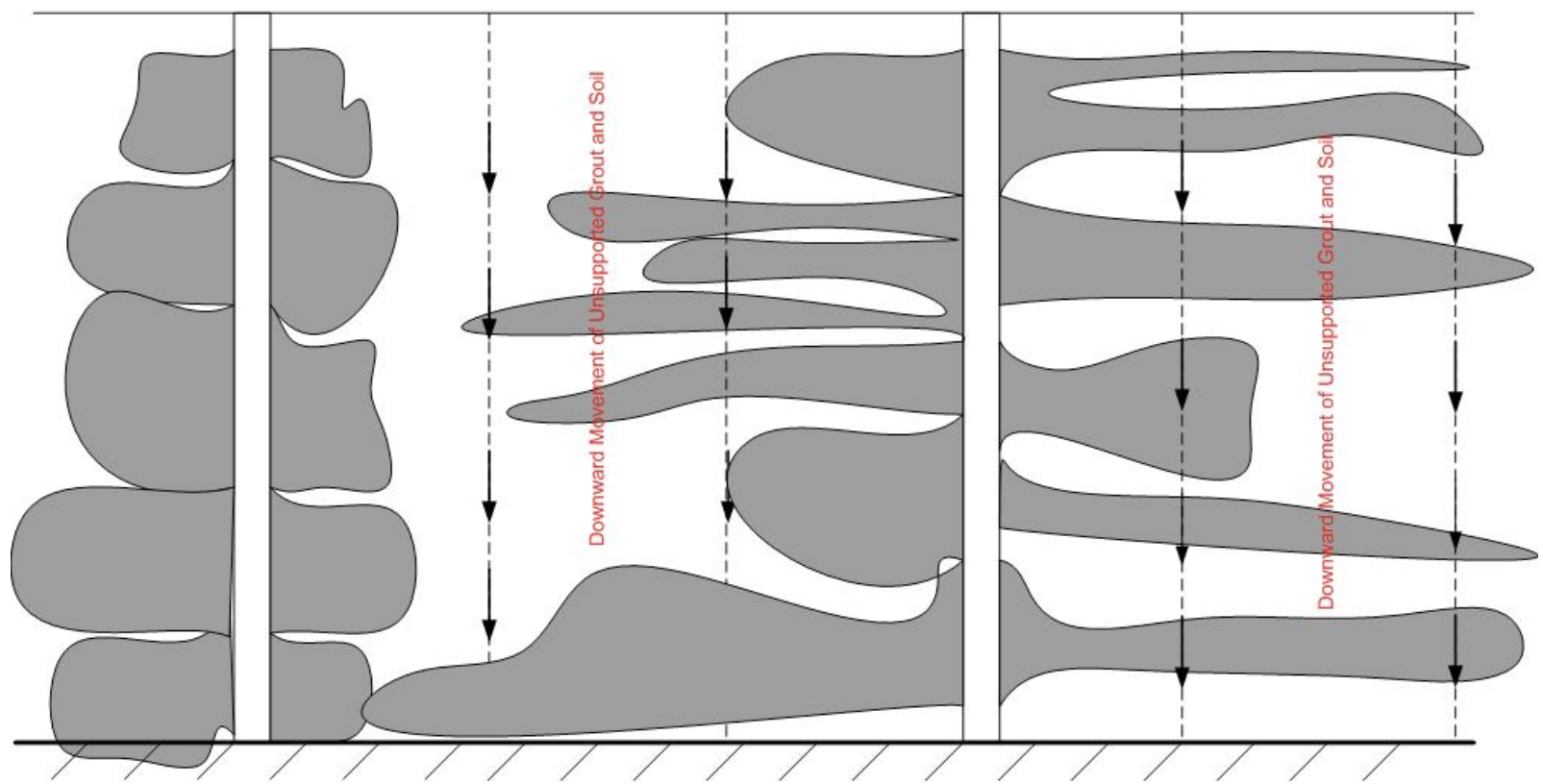

Figure 9. Potential problems with improper grouting.

Grout Flow $>5 \mathrm{cf} / \mathrm{min}$ 
